\title{
Psicologia Escolar em ONGs: Desafios Profissionais e Perspectivas Contemporâneas de Atuação
}

\author{
Pollianna Galvão \\ Universidade CEUMA - São Luís - MA - Brasil \\ Claisy Maria Marinho-Araujo \\ Universidade de Brasília - Brasília - DF - Brasil
}

\begin{abstract}
Resumo
A existência de psicólogos escolares em ONGs educativas é uma realidade recente no Brasil. Esse contexto agrega peculiaridades históricas, políticas e pedagógicas que imprimem características específicas ao trabalho do psicólogo, especialmente por se dedicar à formação das classes populares. Este artigo constitui-se em um ensaio teórico que objetiva discutir aspectos relacionados à atuação do psicólogo escolar em ONGs e apresentar uma proposição de trabalho em Psicologia Escolar ancorado em três grandes eixos de atuação. Na primeira parte do artigo, serão analisadas as perspectivas gerais de atuação da Psicologia Escolar, especialmente vinculadas ao seu compromisso social e político com a educação na atual conjuntura. Dessas considerações, parte-se para uma discussão sobre o contexto histórico das ONGs no país, as contradições desse cenário educativo e as potencialidades para a formação humana, vinculadas ao compromisso com a transformação social na atualidade. Por fim, serão abordados os desafios e as possíveis contribuições do psicólogo escolar em ONGs educativas, delineando uma proposta para a atuação profissional em Psicologia Escolar nesse contexto.
\end{abstract}

Palavras-chave: Psicologia escolar; organizações não governamentais; atuação do psicólogo.

\section{School Psychology in NGOs: Professional Challenges and Contemporary Perspectives of Action}

\begin{abstract}
The existence of school psychologists in educational NGOs is a recent reality in Brazil. This context adds historical, political and pedagogical peculiarities that give specific characteristics to the psychologist's work, especially for dedicating himself to the formation of the working classes. This article is a theoretical essay that aims to discuss aspects related to the performance of the school psychologist in NGOs and present a proposal of work in School Psychology in three main axes of action. In the first part of the article, the general perspectives of School Psychology will be analyzed, especially related to its social and political commitment to education on the current situation. From these considerations, the first part begins with a discussion about the historical context of the NGOs in the country, the contradictions of this educational scenario and the potentialities for human formation, linked to the commitment to the current social transformation. Finally, the challenges and possible contributions of the school psychologist in educational NGOs will be addressed, outlining a proposal for the professional performance in School Psychology in this context.
\end{abstract}

Keywords: School psychology; Non-governmental organizations; psychologist performance.

\section{Psicología escolar en ONGs: Retos Profesionales y Perspectivas Contemporáneas de Actuación}

\begin{abstract}
Resumen
La existencia de psicólogos escolares en ONGs educativas es una realidad reciente en Brasil. Ese contexto agrega peculiaridades históricas, políticas y pedagógicas que imprimen características específicas a la labor del psicólogo, especialmente por dedicarse a la formación de las clases populares. Este artículo se constituye en un ensayo teórico que tiene por objetivo discutir aspectos relacionados a la actuación del psicólogo escolar en ONGs y presentar una propuesta de labor en Psicología Escolar anclado en tres grandes ejes de actuación. En la primera parte del artículo, se analizan las perspectivas generales de actuación de la Psicología Escolar, especialmente vinculadas a su compromiso social y político con la educación en la actual coyuntura. De esas consideraciones, se parte para una discusión sobre el contexto histórico de las ONGs en el país, las contradicciones de ese escenario educativo y las potencialidades a la formación humana, vinculadas al compromiso con la transformación social en la actualidad. Por fin, se aborda-los retos y las posibles contribuciones del psicólogo escolar en ONGs educativas, delineando una propuesta para la actuación profesional en Psicología Escolar en ese contexto.
\end{abstract}

Palabras clave: Psicología escolar; ONG; Actuación del psicólogo. 


\section{Introdução}

\section{Psicologia Escolar na contemporaneidade: ampliando as possibilidades de atuação e compromissos sociopolíticos}

O percurso histórico da Psicologia Escolar no Brasil, como ciência e profissão, vem sofrendo transformações que confirmam uma mudança de paradigma sobre o seu saber e sua prática na contemporaneidade. $O$ contexto de regulamentação e desenvolvimento da profissão, logo nos primeiros anos de 1960, foi marcado por um momento de intensa mobilização popular e crise política em um cenário de ascensão de regimes de Estado que privilegiaram a ideologia liberal e os interesses de classe elitista. Foi nesse panorama que as relações entre a Psicologia e Educação foram fortalecidas, especialmente com a ampliação do sistema público educacional do período, o que representou a expansão dos serviços de atendimento psicológico aos alunos (Antunes, 2003, 2008, 2011; Guzzo, Mezzalira, Moreira, Tizzei, \& Neto, 2010; Marinho-Araujo, 2010, 2014, Neto, Guzzo, \& Moreira, 2014).

A partir de um olhar retrospectivo, autores que versam sobre a história da Psicologia Escolar afirmam que a atuação inicial do psicólogo diretamente na escola fundamentou-se em práticas vinculadas ideologicamente a ações de discriminação, dominação e exclusão educacional, corroborando com práticas que pouco colaboraram com a efetiva transformação social pela escola (Antunes, 2003, 2008,2011; Guzzo, 2005; Guzzo \& cols., 2010; Maluf \&Cruces, 2008, Machado \& Souza, 2004; Marinho-Araujo,2010, 2014; Marinho-Araujo \& Almeida, 2005; Massimi \& Guedes, 2004; Meira, 2012; Patto, 1997, 1999, 2005, 2008; Souza,2004, 2010). Na tentativa de responder às questões da escola, a Psicologia Escolar aliou-se fortemente ao ideário econômico daquele período com base em teorias e práticas psicológicas que desconsideravam o papel da realidade social e propunham soluções corretivas e punitivas às práticas pedagógicas, com base em um modelo clínico e terapêutico de atuação (Dazzani, 2010; Braz-Aquino, Ferreira, \& Cavalcante, 2016). Fortalecida por teorias naturalizantes do desenvolvimento e aprendizagem, a Psicologia desencadeou uma visão reducionista do processo escolar e contribuiu para ocultar as origens políticas e econômicas dos problemas sociais em um período que a educação pública passou a ser vista como meio democrático legítimo para a equalização das desigualdades sociais.

Acompanhando as transformações políticas da democracia e a ampliação dos movimentos sociais que se fortaleceram nos anos 1980'1, a Psicologia Escolar passou a realizar uma crítica interna quanto às suas filiações epistemológicas e às suas formas tradicionais de atuação. Instaurou-se um momento importante de reflexões e questionamentos sobre

1 A década de 1980 foi um período no qual os grupos científicoprofissionais da Psicologia passaram a se politizar mais por meio da criação de sindicatos, organizações sociais e associações de classe, fazendo coro aos demais grupos que se somavam aos movimentos pré-constituintes (Marinho-Araujo, 2010; Yamamoto, 2007). o trabalho realizado em Psicologia Escolar que, até então, pouco considerava a influência dos fatores sociais, políticos e econômicos implicados nos problemas escolares e obstaculizavam a superação das desigualdades sociais pela escola (Antunes, 2011; Guzzo, 2005, 2008; Marinho-Araujo, 2010, 2014; Marinho-Araujo \& Almeida, 2005; Souza, 2010).

Deu-se início, àquela época, a um forte movimento de crítica em busca de alternativas de atuação mais eficazes e coerentes à realidade escolar, caminhando ao encontro dos processos sociopolíticos vinculados à democratização do Estado e à luta pelo enfrentamento e denúncia das injustiças sociais. Diversas transformações na esfera socioeconômica do país foram desencadeadas pelos movimentos de reivindicação por condições menos desiguais em áreas como educação, saúde e trabalho. Marinho-Araujo (2014) afirma que "a mobilização e a participação dos psicólogos junto a outros profissionais, nessas lutas sociais, fortaleceram o período de mudanças nas produções da Psicologia" (p. 154).

Nessa conjuntura histórica, que se entrelaça com as transformações políticas e educacionais do país, observou-se que a Psicologia Escolar passou a assumir uma relação diferente com a sociedade, coadunada a compromissos ideológicos outros que não mais se aliavam com a psicologização dos problemas do cenário educacional (Guzzo \& cols., 2010; Marinho-Araujo, 2010, 2014; Massimi \& Guedes, 2004). Essas mudanças vêm alavancando novos desafios e horizontes da Psicologia Escolar em prol da superação de uma história de desigualdade e de injustiça que se concretiza na realidade das instituições educacionais destinadas aos segmentos populares.

Observou-se que a Psicologia estava comprometida com conservadorismo social na medida em que sustentou a psicologização das questões educacionais, a partir de uma concepção de desenvolvimento focada no sujeito e cujo tratamento detinha ênfase no ajustamento remediativo da conduta do escolar. As diversas críticas endereçadas às bases científicas da Psicologia, que denunciavam posturas alinhadas à manutenção e ao conservadorismo social, trouxeram reflexões de natureza epistemológica e conceitual que redefiniam os referenciais teóricos do fazer em Psicologia Escolar crítica (Patto, 1997).

A atuação do psicólogo nos contextos educativos e o compromisso social da profissão, com base nesses referenciais, têm sido alvos das pesquisas, estudos e relatos de experiências publicados na última década (Assis \& Zanella, 2012; Barboza \& Zanella, 2014; Bisinoto \& Marinho-Araujo, 2014; Campos, 2007; Cavalcante \& Aquino, 2013; Cruz \& Borges, 2013; Galvão \& Marinho-Araujo, no prelo; Marinho-Araujo, 2010, 2014; Soares \& Marinho-Araujo, 2010). Os resultados desses avanços versam, entre outros fatores em comum, sobre a relevância dos aspectos históricos e sociais relacionados aos problemas escolares; as propostas de intervenção voltadas para as ações coletivas com os atores escolares; a atuação do psicólogo escolar junto às políticas públicas; a expansão do trabalho psicológico a contextos educativos emergentes, entre outras temáticas que subsidiam novas práticas em Psicologia Escolar na direção da melhoria da 
qualidade da educação e os desdobramentos à transformação da realidade.

A concepção de homem da qual partem esses trabaIhos concebem as dimensões social, processual e histórica envolvidas nos processos de aprendizagem e desenvolvimento (Vygotsky, 1998). A Psicologia Histórico-Cultural, assim conhecida, compreende uma relação dialética entre o homem, como sujeito de sua história, e o contexto sociocultural, assumindo uma noção de sujeito determinado pela sua interação com a história e a cultura em dado tempo e que se apoia em condições materiais que propulsionam mudanças do próprio sujeito e do seu contexto (Vygotsky, 1998, 2004; Leontiev, 2004; Luria, 1990). Portanto, a compreensão sobre os processos educacionais que atravessam as instituições de ensino deve considerar a história da construção dos significados e sentidos que transformam os processos sociais e individuais ali construídos pelas relações sociais.

Com base nessa concepção de homem que subsidia a atuação crítica em Psicologia Escolar, outros modelos de intervenção vêm sendo publicizados, desta vez, em caráter mais preventivo, relacional e institucional, que demarcam a ruptura de paradigma com a atuação tradicional em Psicologia Escolar (Marinho-Araujo, 2010, 2014; Machado \& Souza, 2004). Compreendendo o desenvolvimento humano como um processo influenciado pelos fatores socioculturais, a área tem se comprometido com uma análise social acerca dos fenômenos escolares, concebendo-os como decorrentes das contradições históricas que se apresentam nas instituições educativas, e contextualizando a sua intervenção nos processos institucionais que influenciam a formação humana para a emancipação e autonomia dos sujeitos (Guzzo, 2005).

A acepção de uma compreensão complexa e dialética sobre o fracasso escolar, propostas de avaliação e intervenção que superem o modelo clínico em favorecimento de uma proposta institucional, a assessoria à escola para o cumprimento de sua função, ampliação das ações que integrem a comunidade escolar entre outras, têm sido formas de atuação do psicólogo respaldada por uma visão crítica. Ao se assumir essa concepção de trabalho, o psicólogo escolar desloca a sua atuação do campo do determinismo, que engessa uma prática educativa com potencial transformador, abrindo espaço para um trabalho criativo, coletivo e com ênfase na instituição (Kupfer, 2004).

Marinho-Araujo $(2010,2014)$ defende a perspectiva de atuação institucional em Psicologia Escolar com base em uma compreensão de ensino que supera a visão de adequação dos alunos aos padrões da escola, expandindo o olhar sobre as múltiplas formas e estilos de apropriação do conhecimento. Essa atuação deve ser capaz de evidenciar contradições e incoerências entre as práticas sociais e o discurso educacional, de modo a oportunizar efetivos processos de conscientização nos atores sobre a natureza dialética de construção do conhecimento.

Partindo da noção do homem como um ser social, o lócus privilegiado da intervenção do psicólogo escolar deve voltar-se às relações e interações que se estabelecem no dia a dia da instituição. A perspectiva de atuação institucio- nal implica o reconhecimento de que as relações sociais que lá ocorrem exercem papel singular no desenvolvimento dos sujeitos e na elaboração contínua de suas práticas. Nessa direção, faz-se mister desenvolver ações e estratégias que contribuam para o desvelamento dos aspectos individuais e coletivos, intra e interpsicológicos, que dificultam o processo educacional (Carvalho, 2008; Mítjans-Martínez, 2007, 2009).

Assim entendida, pode-se afirmar que a Psicologia Escolar crítica compreende que os fenômenos escolares não são um conjunto de elementos particulares e isolados, pois estão sempre atrelados a uma rede de relações da qual as causas individuais derivam em meio à circulação de significados e sentidos. Para intervir nesse complexo processo intersubjetivo, na perspectiva institucional, a atuação psicológica deve estar ancorada em uma visão de que homem e sociedade se constituem dialeticamente em suas relações históricas e sociais, de forma que os significados construídos nas interações possam ser alterados na direção da concepção de desenvolvimento escolar que se deseja assumir.

Nesse sentido, é necessário que o psicólogo escolar oportunize espaços de interlocução com os atores da instituição - educandos, educadores, coordenadores, diretores, funcionários entre outros - cujo foco sejam os aspectos objetivos e subjetivos do processo de apropriação do conhecimento e de desenvolvimento. O compartilhamento de sentimentos, desejos, percepções, valores, expectativas sobre as ações dos sujeitos pode provocar a lucidez sobre a sua prática, os elementos subjacentes e os propósitos que se deseja alcançar. Propiciar ocasiões interativas entre os sujeitos direciona a circulação de sentidos o que, potencialmente, pode redirecionar as suas concepções e comportamentos para implementar uma cultura de sucesso escolar,a partir da tomada de consciência (Carvalho, 2008; Marinho-Araujo \& Almeida, 2005).

A mediação psicológica torna-se meio favorável aos processos de conscientização em contextos educacionais pelos quais se prima pelas mudanças da realidade escolar e se luta contra as injustiças. Concorda-se com Marinho-Araujo (2014, p.157) na afirmação que "a mediação que se supõe fonte de oxigenação na e da escola deve reconhecer e enfrentar as lutas sociais que a perpassam, denunciando a falsa 'igualdade de oportunidades' que camufla a desigualdade social".

Para isso, é importante que o psicólogo escolar construa espaços de circulação das "vozes institucionais", o que exige desse profissional uma competência que lhe é específica: a escuta psicológica (Kupfer, 2004; Marinho-Araujo, 2010, 2014; Marinho-Araujo \& Almeida, 2005). Para trabalhar com esse tipo de atuação, é fundamental que o psicólogo se coloque em situação de ouvir e acolher a demanda singular do sujeito. Contudo, essa escuta e acolhimento não são isentos de um olhar investigativo e questionador do profissional que, com clareza e criticidade, deve buscar gerir e redirecionar as intersubjetividades em favor do sucesso escolar. Por se entender que o encontro dos sujeitos em dado contexto interpsíquico produz novos sentidos e movimenta as ações individuais e coletivas para novos rumos, a sensibilidade para a escuta do psicólogo deve ser revestida por uma ação ativa e propositiva para provocar mudanças na instituição. 
Mitjáns-Martínez $(2007,2009)$ reitera que a perspectiva institucional, com ênfase nos processos de subjetivação dos sujeitos, é uma das formas de atuação emergentes da Psicologia Escolar que pode subsidiar estratégias de trabaIho que visam otimizar o processo educativo. Para a autora, as ações de trabalho na instituição podem explorar novos espaços como, por exemplo, junto à gestão no planejamento e implementação das políticas institucionais.

A partir dessas reflexões, conclui-se que as diretrizes atuais que orientam as práticas em Psicologia Escolar já se distanciam dos modelos tradicionais, que sustentaram por bastante tempo uma postura adaptativa e corretiva dos problemas escolares. Em outra direção, que responde melhor à complexidade inerente dos fenômenos educacionais, os modelos de trabalhos mais contemporâneos estão subsidiados por parâmetros de sucesso escolar como contraponto à cultura de fracasso. O trabalho da Psicologia Escolar, com foco na cultura de sucesso, "privilegia as potencialidades e possibilidades em vez dos problemas e dificuldades, focaliza as diferentes alternativas individuais e coletivas de superação das adversidades, valoriza as diferenças, a heterogeneidade e a diversidade de formas de aprender, pensar e estar no mundo" (Oliveira \& Marinho-Araujo, 2009, p.658).

A despeito desse avanço e das propostas de atuação mais críticas que se figuram, ainda se reconhece, nos dias atuais, a coexistência tanto de modelos críticos e inovadores quanto de práticas ainda fundamentadas em uma visão estigmatizadora e remediativa (Antunes, 2011). A constatação da existência simultânea de modelos de trabalhos inovadores e tradicionais em Psicologia Escolar sugere uma necessidade de maior atenção em se analisar criticamente o trabalho que se desenvolve nas instituições de educação que despontam na atualidade, especialmente o contexto das ONGs que surge para atender às camadas populares da sociedade sob a égide do compromisso social. Nas palavras de Yamamoto (2007), há de se ter o cuidado para se entender que "atuar com compromisso significa não somente superar o elitismo, mas dirigir a ação para rumos diferentes daqueles que têm consagrado a Psicologia" (p. 34), tal como se defende a Psicologia Escolar crítica em ONGs na contemporaneidade.

\section{As ONGs educativas no Brasil: um cenário de contradições, limites e potencialidades à formação humana}

As ONGs educativas no Brasil advêm de uma longa, complexa e contraditória trajetória de ampliação da democracia brasileira. Desde a década de 1960, essas instituições surgiram vinculadas aos movimentos sociais na intenção de se discutir políticas setoriais que pudessem, estrategicamente, beneficiar a parte majoritária da população. A atuação dessas instituições possuía característica militante e reivindicatória, especialmente em frentes sociais que buscavam influenciar a gestão de políticas sociais importantes, como saúde e educação (Dagnino, 2004, 2005; Gohn, 2006, 2009, 2011; Haddad, 2012; Souza, 2009).
De acordo com Medeiros (2007), o surgimento dessas organizações no país comparecia também como uma espécie de solução pontual para problemas e demandas sociais específicas do período. Os centros de educação desenvolvidos paralelamente ao sistema formal de ensino, os centros de pesquisa criados fora das universidades e longe das pressões do Estado autoritário, grupos de apoio a movimentos sociais que surgiam fora do sistema político legal etc., estavam entre as instituições não governamentais que atuavam paralelamente ao Estado (Haddad, 2009, 2012). Contudo, o que não se previu foi que essa tendência viesse a inaugurar novas formas de instituições politicamente atuantes na elaboração e execução das políticas sociais em tempos mais recentes.

O final da década de 1980 foi um período importante no processo da democratização brasileira e no fortalecimento dos movimentos sociais e das ONGs no país nessa direção. A Constituição Federal de 1988 nascia com a promessa de abrir inúmeras portas à consolidação da conquista de direitos por meio de mecanismos descentralizadores das políticas sociais, como saúde, educação, moradia, trabalho, entre outras. Esses mecanismos visavam ampliar os direitos da cidadania por intermédio da responsabilidade social do Estado e da participação civil democrática (Dagnino, 2004, 2005).

Entretanto, a década de 1990 estabeleceu um momento bastante contrário à consolidação de políticas públicas na direção ideológica de sua origem e desenvolvimento. Instaurou-se uma época em que coexistiam forças de um regime político conciliador de interesses liberais e sociais com base no recente pragmatismo político-ideológico internacional do neoliberalismo, que pregava a intervenção mínima do Estado no provimento das políticas sociais, entre as quais a educação (Martins \& Groppo, 2010; Souza, 2009).

Os anos 1990 foram marcados pela criação de fundos públicos de investimento, programas governamentais e iniciativas privadas para responderem às novas exigências legislativas, especialmente aquelas derivadas do Plano Decenal de Educação para Todos (1993-2003) e da Lei de Diretrizes e Bases (LDB), Lei N. ${ }^{\circ} 9.394$ de 1996. Projetos de capacitação docente, programas de compensação à defasagem escolar, ações de combate ao trabalho infantil, incentivos financeiros à permanência da criança na escola, entre outros temas, passaram a ser alvos das políticas educacionais do período (Marinho-Araujo, 2010; Rizzo, 2011; Santos, 2011). Entretanto, essas ações, bem como as constantes mudanças constitucionais, estavam em plena sintonia com as orientações dos organismos internacionais de financiamento, como o Banco Mundial e o FMI, e alinhadas ao conceito de Estado mínimo do neoliberalismo (Gohn, 2011).

Com o avanço neoliberal na década de 1990, foi necessário redefinir as funções do Estado, especialmente com a ascensão da tese de que o setor público brasileiro era ineficaz no cumprimento das medidas constitucionais. O que se observou foi uma diminuição das responsabilidades estatais e o aumento de iniciativas privadas e filantrópicas, especialmente pela terceirização dos serviços que eram atribuídos ao Estado. A reforma do sistema educacional arquitetada ao 
período favorecia a lógica neoliberal à medida que passou a delegar a implementação de programas socioeducativos a outros agentes sociais, como as ONGs, focalizados na oferta de serviços públicos para a população mais pobre (Montaño, 2010). Concorda-se com Santos (2011) na afirmação de que

Capacitação de professores foi traduzida em profissionalização; participação da sociedade civil assumiu a forma de articulação com empresários e ONGs; descentralização significou desobrigação do Estado; autonomia ganhou contorno de liberdade para captação de recurso; melhoria da qualidade da educação traduziu-se em adequação ao mercado, sendo que o aluno se transformou em consumidor. (p. 8)

As tendências educacionais do período foram caracterizadas pela agenda neoliberal de redução de gastos públicos, privatização das empresas públicas, em conformidade às agências financiadoras internacionais guiadas pelo princípio de Estado mínimo (Gohn, 2006, 2009; Souza, 2009; Montaño, 2010). A partir das diversas aberturas legislativas, como a Lei n. 9.790/99, que regulamenta as Organizações da Sociedade Civil de Interesse Público (OSCIP), às ONGs coube prover ações voltadas para o apaziguamento das desigualdades sociais e a dificuldade de acesso aos bancos escolares por meio de fornecimento de serviços educacionais que compensassem a insuficiência das ações do Estado.

No início dos anos 2000, novas expectativas em torno das políticas educacionais reascenderam o espírito socialista desenvolvido nas décadas anteriores. Com o prenúncio da constituição do primeiro governo esquerdista brasileiro, as esperanças sobre a diminuição das desigualdades sociais e da exclusão mobilizaram novamente os representantes civis para a busca de soluções centradas no Estado para a transformação da realidade brasileira. Entretanto, o novo governo seguiu com as reformas iniciadas no governo do presidente anterior, Fernando Henrique Cardoso, em seus primeiros anos, especialmente devido aos acordos estabelecidos com as agências e organismos internacionais. O Plano Nacional de Educação, regulamentado pela Lei 10.172 de 2001 com vigência de 10 anos, foi uma relevante medida legislativa que assegurava a continuidade das políticas e reformas educacionais geridas pelo governo anterior (19992002) (Santos, 2011).

Sader (2013) afirma que, embora o empreendimento dessa gestão tenha ido ao encontro de uma atualização da prática política necessária à superação do neoliberalismo, a intervenção do Estado permaneceu limitada na intenção da recuperação do seu papel ativo na construção dos direitos cidadãos. Apenas em meados dos anos 2000 pôde-se perceber que novas políticas começaram a compor a agenda pública em direção diferente, gerando outros mecanismos para a seguridade dos direitos sociais por intermédio direto do Estado. As políticas afirmativas educacionais, políticas de direitos humanos, discussão sobre a maior idade penal, entre outras agendas, fortaleceram uma valorização de políticas educativas diferentes ideologicamente daquelas gestadas na década anterior.

Isso, em tese, enfraqueceria o papel das ONGs na consecução de programas socioeducativos, porque o governo tomou para si novamente a responsabilidade pela diminuição da pobreza e das desigualdades educacionais. Contudo, o que se constatou foi um crescimento acentuado da quantidade das entidades sem fins lucrativos pela via do terceiro setor (Soares, 2014; Galvão \& Marinho-Araujo, no prelo).

De acordo Souza (2009), as ONGs continuaram a crescer numericamente ao longo dos anos 2000, mas tendo que ressignificar sua missão política na área social da educação e redesenhar sua relação com o Estado. Com o crescimento de políticas públicas voltadas para a superação da pobreza e das desigualdades sociais, houve foi um processo de ressignificação sobre a identidade de todos os setores de participação civil e uma conscientização da sociedade acerca do seu papel junto ao Estado.

Atualmente, a atuação das ONGs nas áreas sociais deve ser concebida com bastante crítica no que se refere à sua relação com o Estado na prática política da atual democracia. As instituições não governamentais de natureza assistencialista, com pretensões de supressão das falhas do sistema público, devem ser substituídas por uma atuação crítica e verdadeiramente emancipadora. Partindo do princípio de que não deve haver complementaridade entre o primeiro e terceiro setor, no que se refere ao atendimento de demandas que são de responsabilidade estatal, podem-se vislumbrar atuações das ONGs em favor da construção da cidadania e da ampliação da seguridade dos direitos civis basilares, como saúde e educação.

As ONGs aparecem no cenário da educação brasileira como um dos elos integradores das demandas sociais oriundas da população de baixa renda e as políticas públicas. Na literatura sobre o terceiro setor, a descentralização das ações do Estado por meio de parceria com as ONGs educativas pode ser analisada em duas direções. Primeiro, essas instituições possibilitam a participação de diversos segmentos da sociedade no provimento das demandas educacionais, com vistas à ampliação das ações para o desenvolvimento cultural da população desfavorecida socioeconomicamente. Sob outro prisma, as ONGs podem servir como suposta alternativa democrática de eficiência do Estado, convindo para ocultar as transformações socioeconômicas e desresponsabilizar as políticas de governo no que diz respeito ao seu papel na oferta de uma educação universal e de qualidade (Dagnino, 2004, 2005; Gohn, 2006, 2009, 2011; Montaño, 2010; Souza, 2009).

$\mathrm{Na}$ interseção dessas compreensões reside um questionamento relevante a esse trabalho: se, por um lado, a universalização e qualidade da educação é um dever do Estado e um direito alienável da população e, por outro, são aspectos desejáveis e alvos de reivindicação da sociedade civil organizada, como essa relação pode desencadear ações que, de fato, conduzam a resultados práticos para as questões educacionais? Como a missão socioeducativa das ONGs pode concretizar uma formação emancipatória, 
desenvolvendo sujeitos engajados na luta contra as desigualdades e injustiças sociais? Qual o compromisso da Psicologia, e em especial da Psicologia Escolar, com o desenvolvimento humano nesses espaços educativos militantes?

A Psicologia Escolar é convidada a atuar nas instituições contemporâneas de educação com clareza e criticidade sobre o sistema educacional em suas diversificadas e complexas dimensões que se transformam ao longo de sua história. O desafio que se coloca há tempos ao psicólogo escolar brasileiro, e que se renova na contemporaneidade, é o seu compromisso com a transformação social nos diferentes espaços educacionais e frente às novas demandas sociopolíticas (Marinho-Araujo, 2010, 2014).

As ONGs, que surgem para oferecer serviços educacionais às classes populares, têm se constituído como um desses cenários que carregam um percurso complexo e contraditório, podendo ora se firmarem como armadilhas da política neoliberal ora como potenciais lócus para a formação humana emancipatória (Caro \& Guzzo, 2004; Dadico \& Souza, 2010; Soares \& Marinho-Araujo, 2010). Há de se ter um processo contínuo e persistente de autocrítica, revisão e ressignificação do perfil do psicólogo escolar que conduza, como desdobramento, a criação de estratégias de intervenção psicológica capazes contribuir com a educação social que se materializam nos espaços alternativos de formação humana. A proposta de atuação profissional da Psicologia Escolar em ONGs educativas, a ser apresentada a seguir, figura uma das possíveis contribuições dessa área no cenário da diversidade da educação brasileira, coerente com a atualização do seu compromisso sociopolítico na contemporaneidade.

\section{O trabalho do psicólogo escolar em ONGs: uma proposta para atuação profissional}

A partir do entendimento de que as ONGs realizam um trabalho que favorece o desenvolvimento da cidadania e emancipação social, por meio da diversidade de atividades culturais e múltiplas linguagens de mediação da aprendizagem, qual poderia ser uma proposta de atuação em Psicologia Escolar que se compromete e potencializa a transformação social? Galvão e Marinho-Araujo (no prelo) defendem que o psicólogo escolar deve subsidiar a sua atuação com clareza, lucidez e criticidade sobre os espaços alternativos da educação não-formal que surgem no complexo sistema da educação brasileira. A constituição das ONGs educativas, nesse cenário, vem aliando-se a distintos propósitos ideológicos contraditórios, decorrentes da história da ampliação dos direitos educacionais que ora se coadunaram aos movimentos de luta pela educação pública de qualidade, ora se aproximaram aos ideários do neoliberalismo corroborando com o conservadorismo e a manutenção social (Gohn, 2006, 2009, 2010; Yamamoto, 2007).

Atenta-se para o fato de que se deve ter o devido cuidado ao propor uma atuação psicológica sem a devida sintonia com os interesses e demandas das classes populares (Yamamoto, 2007). Defende-se que a perspectiva de trabalho do psicólogo escolar no terceiro setor deve ser institucional e criticamente situada no tempo e na história da constituição dessas organizações em supressão de uma atuação psicológica assistencialista, coadunada ao discurso neoliberal de Estado mínimo e próximo aos modelos de atuação historicamente superados pela Psicologia Escolar.

O psicólogo escolar precisa estar atento aos aspectos institucionais que caracterizam as ONGs, sua história, missão, filosofia, estrutura, filiações governamentais e/ou não governamentais, em suas convergências, divergências e incoerências práticas que possam vir a ser obstáculos ao potencial transformador da educação emancipatória investida pela organização. A intervenção institucional, tal como se defende a atuação crítica em Psicologia Escolar, pode ser feita nesses espaços na direção de se conscientizar os atores quanto aos seus papéis, funções e responsabilidades contextualizadas à conjuntura da escola e demais setores sociais (Marinho-Araujo, 2014; Soares \& Marinho-Araujo, 2010).

A defesa do trabalho da Psicologia Escolar em ONGs deve orientar propostas de atuação com base em uma visão crítica da realidade, dos fenômenos sociais e culturais para planejar uma atuação de combate à alienação, à adaptação e à falta de clareza por parte das pessoas com relação aos mecanismos de controle social. A atuação crítica nesse cenário emergente de trabalho deve ressignificar as proposições de intervenção do psicólogo escolar para o estabelecimento de práticas inovadoras, favorecendo a criação de condições potencializadoras da mediação educativa no contexto do terceiro setor.

Neste artigo são defendidas algumas linhas de intervenção para o desenvolvimento de um trabalho em redes de integração com os setores sociais, compreendendo a ONG como um dos espaços comunitários juntamente com a escola, família e outras instituições sociais. As dimensões propostas foram baseadas e adaptadas de Marinho-Araujo (2014) e são coerentes à Lei de Diretrizes e Bases da Educação (Lei N. ${ }^{\circ}$ 9.394, 1996) e aos Parâmetros Curriculares Nacionais (Ministério da Educação, 1997), marcos legislativos que preveem a participação das instituições da sociedade civil no atendimento educacional.

As atividades sugeridas pautam-se em três grandes eixos de atuação: (1) assessoria à gestão institucional; (2) acompanhamento ao trabalho coletivo dos educadores sociais e (3) acompanhamento ao processo socioeducativo dos educandos. Partindo desse entendimento, sugere-se, a seguir, um conjunto de ações do psicólogo escolar para cada uma das dimensões, como propostas que podem fundamentar o trabalho desse profissional no cotidiano da ONG.

\section{Dimensão 1: assessoria à gestão institucional}

- Assessoria ao gestor na construção de documentos concernentes à política institucional da ONG, como a proposta pedagógico-institucional de educação não-formal entre outros, que estejam em sintonia com as reais demandas da comunidade local. 
- Planejamento de reuniões para a discussão e análise dos documentos orientadores da ONG pelos gestores e educadores sociais, de modo que os significados que compõem as suas diretrizes reflitam as necessidades do cotidiano institucional em sua diversidade.

- Planejamento de ações de capacitação e formação continuada em serviço que envolvam o nivelamento do saber científico da educação não-formal, da leitura crítica sobre papel das instituições de terceiro setor e os processos de desenvolvimento individual e social que podem ser ampliados pela ONG.

- Assessoria ao coordenador pedagógico no planejamento de ações que visem a busca por parceiros governamentais e empresariais, em uma perspectiva para além do fomento às atividades da ONG, contemplando ações que incentivem a aproximação dos agentes financiadores junto aos educadores, educandos, famílias, escolas e comunidade.

- Acompanhamento do processo de implementação das políticas institucionais de forma crítica, identificando pontos que possam ser obstáculos para o processo de mudanças e ajudando no delineamento de ações coletivas para a sua superação.

\section{Dimensão 2: acompanhamento ao trabalho coletivo dos educadores sociais}

- Elaboração de reuniões, oficinas, estudos de caso que se constituam espaços para a interlocução e reflexão do grupo sobre o trabalho pedagógico realizado junto aos educandos, família, escola e comunidade, incentivando o compartilhamento de ações bem-sucedidas e dos desafios a serem superados.

- Criação de espaços de escuta psicológica ao educador, em momentos individuais e/ou coletivos, provocando a tomada de consciência sobre o potencial de reinvenção das práticas educativas, bem como a ressignificação do olhar sobre o processo do ensino para os educandos.

- Elaboração de oficinas que visem, especificamente, potencializar a intencionalidade da equipe quanto ao planejamento e realização das atividades educativas, de forma que as ações de sucesso deixem de ser pontuais para se tornarem resultados dos objetivos do trabalho previamente traçados.

- Acompanhamento e incentivo aos momentos coletivos de estudos teóricos articulados aos estudos de caso derivados do dia a dia institucional, com vistas a desenvolver empoderamento do educador em situações específicas de superação dos problemas.
- Elaboração de propostas de formação dos educadores sociais, com base no conhecimento da Psicologia, visando oxigenar as concepções sobre o educando pertencente à classe popular, em prol da construção de uma noção de sujeito histórico e protagonista de sua formação.

- Incentivo à articulação dos saberes da prática do educador social, seu conhecimento sobre a realidade comunitária dos educandos e os conhecimentos técnicos, teóricos e metodológicos da Educação, de modo que possa auxiliar a resolução de tarefas e de situações-problema em sala de aula e na intervenção pedagógica junto à família e comunidade.

\section{Dimensão 3: acompanhamento ao processo socioeducativo dos educandos}

- Criação de espaços de interlocução individual e coletiva para conscientizar sobre a função dos educadores sociais como agentes de desenvolvimento humano, a partir da compreensão de que a mediação pedagógica leva a ampliação qualitativa da formação dos processos psicológicos dos educandos.

- Incentivo a elaboração criativa de projetos socioeducativos, integrados às múltiplas linguagens de apreensão do conhecimento humano com vistas à promoção de uma cultura cívica entre os educandos, fortalecendo a construção de processos psicológicos que favoreçam a uma leitura crítica da realidade.

- Implementação de projetos em Psicologia Escolar que visem à ampliação de uma cultura de sucesso, em supressão da perspectiva de fracasso escolar.

- Acompanhamento da rotina dos educadores na consecução de suas oficinas (artes, música, dança etc.) e nos inúmeros espaços que se constroem no dia a dia institucional, a fim de mobilizar continuamente a ressignificação dos fenômenos da educação social.

- Incentivo à protagonização dos estudantes na elaboração de projetos discentes filiados às atividades pedagógicas das ONGs, incitando características de liderança, competências pessoais e interpessoais, ética e solidariedade com o seu grupo comunitário e espírito cívico para a transformação da realidade local.

A proposta apresentada não esgota as diversas possibilidades de atuação da Psicologia Escolar em ONG e deve ser alvo de contínuo um exercício reflexivo ao qual novas proposições podem somar, ampliar e revisar criticamente, seja com base na consecução de estudos e pesquisas ou pela experiência da prática profissional. 
Perante a ascensão das ONGs educativas no país, e o compromisso da Psicologia Escolar com a formação humana, este ensaio é um convite para que os psicólogos ampliem a dimensão política de suas ações profissionais e assumam esses espaços com clareza e criticidade das contradições que os constituem, seguros dos pressupostos ideológicos que norteiam a sua atividade política e inspirados em orientações teórico-metodológicas contemporâneas para a consecução do seu trabalho.

\section{Considerações Finais}

Este artigo partiu do entendimento de que o trabalho de psicólogos escolares em ONGs de natureza educativas já é uma realidade no Brasil, uma vez que o terceiro setor tem sido uma via de legitimidade e crescimento da participação civil no atendimento das demandas sociais. Não é por acaso, nas últimas décadas, as ONGs têm crescido e se expandido por todo o território nacional por meio de Fundações e Associações sem fins lucrativos, conhecidas como FASFIL. De acordo com a última pesquisa divulgada pelo Instituto Brasileiro de Geografia e Estatística (IBGE, 2012), foram registradas, em 2010, mais de 570.000 entidades sem fins lucrativos, das quais se destacava o campo de Educação e Pesquisa com a quantidade de 87.948 instituições dessa natureza.

Dada a magnitude desse contexto, ao qual o psicólogo escolar tem sido convidado a atuar, é necessário levantar reflexões críticas sobre a natureza do trabalho a ser empreendido nesses espaços. Desse cenário do terceiro setor, desmembram-se instituições educativas alternativas para a prática da educação não-formal (Caro \& Guzzo, 2004), cujas atividades carregam peculiaridades históricas, políticas e pedagógicas de formação das classes populares em prol de uma cultura cívica, que deve imprimir características específicas ao trabalho do psicólogo.

É necessário que o profissional seja capaz de circunstancializar a sua atuação na conjuntura da história de injustiças sociais que justificam a existência das ONGs no país e que dão abertura a um novo campo de atuação em Psicologia Escolar. Esse contexto emergente requer o desenvolvimento de um trabalho que não se desloque do campo político para o da caridade e da assistência básica.

A partir da sua especificidade de atuação, o psicólogo escolar pode mobilizar ações e atividades que provoquem uma mudança das noções de aprendizagem, desenvolvimento e ensino que engessam a concretização de uma educação social com potencial transformador. Por ser um espaço cuja concepção, em grande parte, advém da ideia de assistir às camadas populares da sociedade, podem trazer consigo a compreensão de que o sujeito assistido pela instituição é "carente", excluído e privado das possibilidades de ascensão social. Assumir tal entendimento pode enfraquecer uma proposta formativa com potencial para a emancipação. Nesse sentido, o psicólogo escolar deve desenvolver um trabalho visando mediações que levem os atores das ONGs à conscientização de seus papéis e responsabilidades como agentes de formação humana emancipatória, a partir da ruptura com noções passivas de desenvolvimento e em favor do estabelecimento de uma compreensão de sujeito ativo e protagonista de sua história de vida.

Pelo reconhecimento de que as ONGs educativas detêm, em sua missão sociopolítica, um compromisso social voltado para o desenvolvimento humano, fator que as aproxima dos propósitos profissionais do psicólogo escolar, defende-se que a Psicologia Escolar deve ressignificar sua práxis para atender às demandas desse campo em favorecimento do ativismo popular para a transformação social. Cabe ao profissional da Psicologia a realização de uma constante análise crítica sobre si, no que diz respeito à atualização do seu perfil profissional e ao compromisso com sua formação continuada, situando-se na história da pesquisa e intervenção em Psicologia Escolar e na expansão de sua atuação nos contextos educativos contemporâneos. É importante que o psicólogo escolar invista em sua própria formação na intenção de consolidar competências que lhe fornecerão segurança para atuação, em consonância à clareza do perfil profissional necessário a esses espaços.

\section{Referências}

Antunes, M.A.M. (2003). Psicologia e educação no Brasil: um olhar histórico-crítico. Em M.E.M. Meira \& M.A.M. Antunes (Orgs.), Psicologia escolar: teorias críticas (pp. 139-168). São Paulo: Casa do Psicólogo.

Antunes, M.A.M. (2008). Psicologia Escolar e educacional: história, compromisso e perspectivas. Psicologia Escolar e Educacional 12 (2), 469-475.

Antunes, M.A.M. (2011). Psicologia e Educação no Brasil: uma análise histórica. Em R.G. Azzi \& M.H.T. Gianfaldoni (Orgs.), Psicologia e Educação (pp. 9-32). São Paulo: Casa do Psicólogo.

Assis, N. \& Zanella, A. V. (2012). Jovens e Programas de Contraturno Escolar: (des)encontros possíveis. Pesquisas e Práticas Psicossociais, 7, 76-82.

Barboza, D. \& Zanella, A.V. (2014). Relações estéticas dos catadores de material reciclável com a cidade: os passos da pesquisa. Psicologia \& Sociedade, 26, 53-62.

Bisinoto, C. \& Marinho-Araujo, C.M. (2014). Serviços de Psicologia Escolar na Educação Superior: uma proposta de atuação. Em R.S.L. Guzzo (Org.), Psicologia Escolar: Desafios e Bastidores na Educação Pública (pp. 277-296). Campinas: Alínea.

Braz-Aquino, F.S.; Ferreira, I. R. L., \& Cavalcante, L.S. (2016). Concepções e Práticas de Psicólogos Escolares e Docentes acerca da Inclusão Escolar. Psicologia: Ciência e Profissão, 36 (2), 255-266. 
Campos, H. R. (Ed.) (2007). Formação em Psicologia Escolar: realidades e perspectivas. Campinas: Alínea.

Caro, S.M.P. \& Guzzo, R.S.L. (2004). Educação social e psicologia. Campinas: Alínea.

Carvalho, R.G.G. (2008). A dimensão relacional da intervenção dos serviços de Psicologia nas escolas. Psicologia: Reflexão e Crítica, 21 (1), 119-124.

Cavalcante, L.A. \& Aquino, F.S.B. (2013). Ações de psicólogos escolares de João Pessoa sobre queixas escolares. Psicologia em Estudo, 18 (2), 353-362.

Cruz, D.R.M. \& Borges, L.C. (2013). A queixa escolar: reflexões sobre o atendimento psicológico. Psicologia Argumento, 31 (72), 79-87.

Dadico, L. \& Souza, M.P.R. (2010). Atuação do psicólogo em organizações não governamentais na área da educação. Psicologia, Ciência e Profissão, 30 (1), 114-131.

Dagnino, E. (2004). Construção democrática, neoliberalismo e participação: os dilemas da confluência perversa. Política \& Sociedade, 1 (5), 137-161.

Dagnino, E. (2005). Políticas culturais, democracia e o projeto neoliberal. Revista Rio de Janeiro, 15, 45-65.

Dazzani, M.V.M. (2010). A Psicologia Escolar e a educação inclusiva: uma leitura crítica. Psicologia, Ciência e Profissão, 30 (2), 362-375.

Galvão, P. \& Marinho-Araujo, C.M. (no prelo). ONGs no Brasil: Contextualização Histórica do Cenário para Atuação em Psicologia Escolar. Revista em Psicologia.

Gohn, M.G. (2006). Educação não-formal, participação da sociedade civil e estruturas colegiadas nas escolas. Ensaio, 14 (50), 27-38.

Gohn, M.G. (2009). Educação não-formal, educador(a) social e projetos sociais de inclusão social. Meta: Avaliação, 1(1), 28-43.

Gohn, M.G. (2011). Educação não formal e cultura política: impactos sobre o associativismo do terceiro setor ( $5^{\mathrm{a}}$ ed.). São Paulo: Cortez.

Guzzo, R.S.L. (2005). Escola amordaçada: compromisso do psicólogo com este contexto. Em A. Mitjáns-Martinez (Org.), Psicologia escolar e compromisso social: novos discursos, novas práticas (pp. 17-29). São Paulo: Alínea.

Guzzo, R.S.L. (2008). Psicologia em instituições escolares e educativas. Em Conselho Federal de Psicologia. Ano da Psicologia na Educação Textos Geradores. Brasília: CFP.

Guzzo, R.S., Mezzalira, A.S.C, Moreira, A.P.G., Tizzei, R.P., \& Neto, W.M.F.S. (2010). Psicologia e Educação no Brasil: uma visão da história e possibilidades nessa relação. Psicologia: Teoria e Pesquisa, 26, 131-141.
Haddad, S. (2009). A participação da sociedade civil brasileira na educação de jovens e adultos e na CONFINTEA VI. Revista Brasileira de Educação, 14, 355-369.

Haddad, S. (2012). Direito à Educação. Em R.S. Caldart, I.B Pereira, P. Alentejano, \& G. Frigotto. (Orgs.), Dicionário da Educação no Campo (pp. 215-223). São Paulo: Expressão Popular.

Instituto Brasileiro de Geografia e Estatística [IBGE] (2012). As Fundações e Associações Sem Fins Lucrativos no Brasil 2010. Rio de Janeiro:IBGE.

Kupfer, M.C.M. (2004). O que toca à/a psicologia escolar. Em A.M. Machado e M.P.R. de Souza (Orgs.),Psicologia escolar: em busca de novos rumos (pp.55-65). São Paulo: Casa do Psicólogo.

Lei N. 9.394 de 20 de Dezembro de 1996. Diário Oficial da União, Seção 3, p. 27833 de 23 de Dezembro de 1996. Disponível em http://www.planalto.gov.br/ccivil_03/leis/L9394.htm

Lei N. ${ }^{\circ} 9.790$ de 23 de Março de 1999. Diário Oficial da União, Seção 1, p. 1 de 24 de Março de 1999. Disponível em http://www2. camara.leg.br/legin/fed/lei/1999/lei-9790-23-marco-1999-349541norma-pl.html

Leontiev, A. (2004). O desenvolvimento do psiquismo. Trad. Rubens Eduardo Frias. $2^{\mathrm{a}}$ Ed. São Paulo: Centauro.

Luria, A.R. (1990). Desenvolvimento cognitivo. São Paulo: Ícone.

Machado, A.M. \& Souza, M.P. (Orgs.) (2004). Psicologia escolar: em busca de novos rumos. São Paulo: Casa do Psicólogo.

Maluf, M.R. \& Cruces, A.V.V. (2008). Psicologia educacional na contemporaneidade. Boletim Academia Paulista de Psicologia, 1 (8), 71-99.

Marinho-Araujo, C.M. (2010). Psicologia Escolar: pesquisa e intervenção. Em Aberto, 23 (83), 17-35.

Marinho-Araujo, C.M. (2014). Intervenção institucional: ampliação crítica e política da atuação em Psicologia Escolar. Em R. S. L. Guzzo (Org.), Psicologia escolar: desafios e bastidores na educação pública (pp. 153-176). Campinas: Alínea.

Marinho-Araujo, C. M. \& Almeida, S. F. C. (2005). Psicologia escolar: construção e consolidação da identidade profissional. Campinas: Alínea.

Massimi, M. \& Guedes, M.C. (2004). História da Psicologia no Brasil: novos estudos. São Paulo: Educ.

Medeiros, R.S. (2007). Crítica e resignação nas atuais relações entre as ONGs e o Estado no Brasil. Em E. Dagnino \& L. Tatagiba (Orgs.), Democracia, sociedade civil e participação (pp. 167-202). Chapecó: Argos. 
Meira, M.E.M. (2012). Para uma crítica da medicalização na educação. Psicologia Escolar e Educacional, 16 (1), 135-142.

Ministério da Educação (1997). Parâmetros Curriculares Nacionais: introdução aos parâmetros curriculares nacionais. Brasília: MEC/SEF.

Mitjáns-Martínez, A. (2007). O psicólogo escolar e os processos de implantação de políticas públicas: atuação e formação. Em H. R. Campos (Org.), Formação em Psicologia Escolar: realidades e perspectivas (pp. 47-59). Campinas: Alínea.

Mitjáns-Martínez, A. (2009). Psicologia Escolar e Educacional: compromissos com a educação brasileira. Psicologia Escolar e Educacional, 13 (1), 169-177.

Montãno, C. (2010). Terceiro setor e a questão social: crítica ao padrão emergente de intervenção social (6 ${ }^{a}$ Ed.). São Paulo: Cortez.

Neto, W.M.F.S., Guzzo, R.S.L. \& Moreira, A.P.G. (2014). Estagiários de Psicologia na Escola: o que os bastidores revelam para a formação profissional? Em R.S.L. Guzzo (Org.), Psicologia escolar: desafios e bastidores na educação pública (pp. 197-216). Campinas: Alínea.

Oliveira, C.B.E. \& Marinho-Araujo, C.M. (2009). Psicologia Escolar: cenários atuais. Estudos e Pesquisas em Psicologia, 9 (3), 648-663.

Patto, M.H.S. (1997). A família pobre e a escola pública: anotações sobre um desencontro. Em M.H.S. Patto (Org.), Introdução à psicologia escolar (pp. 281-296). São Paulo: Casa do Psicólogo.

Patto, M.H.S. (1999). A produção do fracasso escolar: histórias de submissão e rebeldia. São Paulo: Casa do Psicólogo.

Patto, M.H.S. (2005). Exercícios de indignação: escritos de educação e psicologia. São Paulo: Casa do Psicólogo.

Patto, M.H.S. (2008). Ciência e política na Primeira República: origens da Psicologia Escolar. Em A. M. Jacó-Vilela, F. Jabur, \& H. B. C. Rodrigues (Eds.), Clio-Psyché: Histórias da Psicologia no Brasil (pp. 187-206). Rio de Janeiro: Biblioteca Virtual de Ciências Humanas do Centro Edelstein de Pesquisas Sociais.
Rizzo, G. (2011). Uma reflexão sobre inclusão, pobreza e acesso ao sistema educacional no Brasil recente. Revista Teias, 12 (24), 09-21.

Sader, E. (2013). Apresentação. Em E. Sader (Org.), 10 Anos de Governos Pós-Neoliberais no Brasil: Lula e Dilma (pp. 7-9). São Paulo: Boitempo.

Santos, S.L.O. (2011). Política Educacional e a Reforma do Estado no Brasil. Dissertação de mestrado não publicada, Universidade Federal Fluminense, Rio de Janeiro.

Soares, P.G. (2014). Psicologia Escolar em Organização Não Governamental: um Estudo Sobre o Perfil Profissional. Tese de doutorado não publicada, Universidade de Brasília, Brasília.

Soares, P.G. \& Marinho-Araujo, C.M.M. (2010). Psicologia Escolar em contextos de Educação Social: práticas emergentes. Psicologia Escolar e Educacional, 14 (1), 45-54.

Souza, D.D.L. (2009). Movimentos sociais, ONGs e educação: um estudo de caso. Aparecida, São Paulo: Ideias \& Letras.

Souza, M.P.R. (2004). A queixa escolar e o predomínio de uma visão de mundo. Em A. M. Machado \& M. P. R. de Souza (Orgs), Psicologia escolar: em busca de novos rumos (pp. 143-158). 4 ed. São Paulo: Casa do Psicólogo.

Souza, M.P.R. (2010). Psicologia Escolar e políticas públicas em Educação: desafios contemporâneos. Em Aberto, 23 (83), 129-149.

Vygotsky, L.S. (1998). A formação social da mente. São Paulo: Martins Fontes. (Texto original publicado em 1926-1927).

Vygotsky, L.S. (2004). Teoria e método em psicologia. São Paulo: Martins Fontes. (Textos originais publicados em 1926).

Yamamoto, O.H. (2007). Políticas sociais, "terceiro setor" e "compromisso social": perspectivas e limites do trabalho do psicólogo. Psicologia \& Sociedade, 19 (1), 30-37.

Recebido em: 17 de junho de 2016 Aprovado em: 19 de junho de 2017

\section{Sobre as autoras}

Pollianna Galvão (polliannagalvão@yahoo.com.br)

Doutora em Processos de Desenvolvimento Humano e Saúde, pelo Instituto de Psicologia da Universidade de Brasília. Professora e pesquisadora da Coordenação de Psicologia da Universidade CEUMA - Campus Renascença em São Luís- MA.

Claisy Maria Marinho-Araujo (claisy@unb.com)

Professora e pesquisadora do Programa de Pós Graduação em Processos de Desenvolvimento Humano e Saúde do Instituto de Psicologia da Universidade de Brasília- Brasília. 